\title{
Empirical Study on the relationship between logistics development and carbon emissions of logistics industry in Guangdong
}

\author{
Lu Xiaping
}

School of business administration, Heyuan Polytechnic, Heyuan City, GuangDong province, china East Ring Road University Town, Yuan Cheng District, Heyuan, Guangdong

393822661@qq.com

Keywords: Development of logistics industry, carbon emissions of logistics industry, VAR.

\begin{abstract}
Based on the sample data of Guangdong Province from 2000 to 2016, this paper conducts a unit root test, cointegration test and Granger causality test on the development of logistics industry and carbon emissions of logistics industry in Guangdong Province. The empirical results show that there is a long-term equilibrium relationship between the development of logistics industry and carbon emissions of logistics industry in Guangdong Province. Carbon emissions are not Granger of the development of logistics industry. The development of logistics industry is the Granger cause of carbon emission of logistics industry. The strategy of low-carbon development of logistics industry in Guangdong Province is put forward to promote the healthy and sustainable development of logistics industry in Guangdong Province.
\end{abstract}

\section{Introduction}

With the global shortage of resources, environmental degradation and other issues highlighted, vigorously developing a low-carbon economy has become a global consensus, modern logistics is a major energy consumption, but also carbon emissions, occupies a special position in the low-carbon economy. In recent years, the logistics industry in Guangdong Province has developed well, and has a great impact on carbon emissions. Studying the relationship between logistics industry and carbon emissions in Guangdong Province, and putting forward low-carbon development strategy, plays an important role in the healthy and sustainable development of logistics industry in Guangdong Province.

At present, there are many papers on carbon emissions, but there are few papers on carbon emissions of logistics industry. Liang Wen studies the dynamic relationship between logistics industry and carbon emissions in Anhui Province based on VAR model. The results show that the development of logistics industry will lead to the increase of carbon emissions, but when the development of logistics industry reaches a certain degree, people will be aware of environmental protection[1]; Ouyang Qiangbin estimates the carbon emission value of the logistics industry by using the carbon emission calculation formula, analyzes the change rule and the reason of the carbon emission, and puts forward the logistics industry low carbon countermeasures [2]; This paper empirically studies the relationship between the development of logistics industry and carbon emissions of logistics industry in Guangdong Province, and puts forward countermeasures for the development of low-carbon logistics industry in Guangdong Province.

\section{Estimation of carbon emissions in Guangdong's logistics industry}

There is no direct data to collect data on Guangdong's carbon emissions. According to the IPCC "bottom-up" method, this paper estimates the carbon emissions of logistics industry in Guangdong Province. The calculation formula is as follows:

$$
C=\sum_{i=1}^{n} E_{i} H_{i} T_{i}
$$

Note: $E_{i}$ is the consumption of certain energy; 
$H_{i}$ is the coal folding coefficient of a certain energy source;

$T_{i}$ is the carbon emission coefficient of a certain energy.

Considering the representativeness and measurability, raw coal, oil and electricity are selected to calculate the carbon emissions of Guangdong logistics industry. According to the China Energy Statistics Yearbook 2000-2016, the coal folding coefficient and carbon emission coefficient of these three kinds of energy are shown in table 1.

Table 1.coal folding coefficient and carbon emission coefficient of energy.

\begin{tabular}{lccc}
\hline Energy type & raw coal & electricity & raw oil \\
\hline coal folding coefficient & 0.7143 & 0.1229 & 1.4728 \\
\hline carbon emission coefficient & 0.7559 & 2.2132 & 0.5714 \\
\hline
\end{tabular}

The paper selects the energy consumption of transportation, post and telecommunications industry to represent the energy consumption of the logistics industry.According to the energy consumption data of Guangdong transportation industry in China Energy Statistics Yearbook 2000-2016, using the formula (1),the carbon emissions and total amount of each energy source in Guangdong Province are calculated, as shown in Table 2.

Table 2. carbon emissions in logistics industry

\begin{tabular}{ccccc}
\hline Year & carbon emissionof crude oil & carbon emission of electricity & carbon emission of raw oil & total \\
\hline 2000 & 6.932821511 & 5.1163628 & 503.34235 & 515.39154 \\
\hline 2001 & 6.193104574 & 6.2587724 & 551.62657 & 564.07845 \\
\hline 2002 & 3.380020456 & 7.5752634 & 601.01171 & 611.96700 \\
\hline 2003 & 3.293630157 & 13.412432 & 690.96415 & 707.67022 \\
\hline 2004 & 3.774176196 & 16.49965 & 811.81558 & 832.08941 \\
\hline 2005 & 0.755915118 & 8.279749 & 1001.640769 & 1010.6764 \\
\hline 2006 & 0.809909055 & 8.834634 & 1034.865916 & 1044.5104 \\
\hline 2007 & 0.901698748 & 10.129365 & 1141.386425 & 1152.4174 \\
\hline 2008 & 0.961092079 & 10.744090 & 1235.873367 & 1247.5785 \\
\hline 2009 & 1.009686622 & 12.294503 & 1326.479354 & 1339.7835 \\
\hline 2010 & 1.101476315 & 14.796924 & 1456.999275 & 1472.8976 \\
\hline 2011 & 1.166269039 & 17.759029 & 1519.136239 & 1538.0615 \\
\hline 2012 & 1.312052669 & 18.526075 & 1537.246148 & 1557.0842 \\
\hline 2013 & 1.425439937 & 19.600484 & 1763.848062 & 1784.8739 \\
\hline 2014 & 2.325172765 & 20.541612 & 1580.631184 & 1603.4979 \\
\hline 2015 & 2.386789844 & 22.418428 & 1642.224429 & 1667.0296 \\
\hline 2016 & 2.452404619 & 25.013330 & 1828.648563 & 1856.1142 \\
\hline
\end{tabular}

From table 2, it can be seen that the carbon emissions of oil products in Guangdong Province are very large, all of which reach over $95 \%$. The total amount of carbon emissions is relatively large, basically showing an upward trend, and the total carbon emission of 2016 is 3.6 times that of 2000 .

\section{Selection of indicators and data sources}

Total carbon emissions of the logistics industry are represented by tpf, and the specific data are shown in Table 2. The development of logistics industry is represented by the added value of logistics industry (gdp). Considering the availability of data, it is replaced by the added value of transportation and postal industry. The data comes from Guangdong Statistical Yearbook 2000-2016. The raw data are shown in Table 3.

Table 3. logistics industry development and logistics industry carbon emission data

\begin{tabular}{cccccc}
\hline Year & $\begin{array}{c}\text { carbon emission of } \\
\text { logistics industry(tpf) }\end{array}$ & $\begin{array}{c}\text { added value of logistics } \\
\text { industry(gdp) }\end{array}$ & Year & $\begin{array}{c}\text { carbon emission of } \\
\text { logistics industry(tpf) }\end{array}$ & $\begin{array}{c}\text { added value of logistics } \\
\text { industry(gdp) }\end{array}$ \\
\hline 2000 & 515.3915405 & 908.45 & 2009 & 1339.783544 & 1595.34 \\
\hline 2001 & 564.0784505 & 1073.81 & 2010 & 1472.897676 & 1825.29 \\
\hline
\end{tabular}




\begin{tabular}{llllll}
\hline 2002 & 611.9670008 & 1157.75 & 2011 & 1538.061537 & 2090.36 \\
\hline 2003 & 707.6702224 & 1207.67 & 2012 & 1557.084276 & 2367.46 \\
\hline 2004 & 832.0894145 & 1351.62 & 2013 & 1784.873986 & 2450.51 \\
\hline 2005 & 1010.676433 & 990.53 & 2014 & 1603.497969 & 2740.76 \\
\hline 2006 & 1044.510459 & 1113.77 & 2015 & 1667.029647 & 2928.9 \\
\hline 2007 & 1152.417489 & 1254.58 & 2016 & 1856.114297 & 3208.35 \\
\hline 2008 & 1247.578549 & 1328.14 & & & \\
\hline
\end{tabular}

\section{Empirical analysis}

\subsection{ADF unit root test}

Before regression analysis, we must test the stationarity of time series data first.In order to reduce the fluctuation of time series, the data are processed logarithmically. The ADF tests of lngdp and lntpf are carried out by EVIEWS software. The results are shown in Table 4. The ADF values of both of them are greater than the critical value of 5\% as shown in Table 4.the date are not stable, so the data for first-order differential processing, and then ADF test, at this time Dlngdp and Dlntpf ADF values are less than $5 \%$ of the critical value, the data is stable, belong to the same order sequence, can be further co-integration test.

Table 4.ADF test.

\begin{tabular}{ccccc}
\hline variable & $5 \%$ critical value & ADF & P-value & stablity \\
\hline lngdp & -3.175352 & -1.238603 & 0.6165 & unstable \\
\hline lntpf & -3.259808 & -2.665356 & 0.1161 & unstable \\
\hline Dlngdp & -3.172257 & -3.212696 & 0.0351 & stable \\
\hline Dlntpf & -3.081002 & -3.464963 & 0.0161 & stable \\
\hline
\end{tabular}

\subsection{Cointegration test}

The number of variables studied in this paper is only two, and the EG two step method is used for cointegration test. Lngdp was used as independent variable and lntpf as a dependent variable for regression analysis. The result was found in equation (1).

$$
\begin{gathered}
\text { Lntpf }=-4.681+0.902 \text { lngdp } \\
\mathrm{t} \quad(-2.524) \quad(6.3107) \\
\text { R-squared }=0.739903 \quad \text { adjusted R-squared }=0.721324 \quad \text { D.W }=0.259859
\end{gathered}
$$

Since the value of $\mathrm{D} . \mathrm{W}$ is far less than 2 , there may be autocorrelation in the residual sequence. Using EVIEWS software to test the unit root of the residual ût, the test results are shown in Table 5. The ADF value of the residual sequence is greater than the critical value of $5 \%$, so the residual data is not stable. Therefore, adding AR (1) to the regression analysis, a new regression equation is obtained as shown in equation (2). At this time, the value of D.W is greater than 2 , and the ADF value of the new residue $\hat{e}_{t}$ is less than $5 \%$ critical value. After adding AR (1), the residue sequence is stable, and the AR root diagram shows that there is no root greater than 1, so it is a stationary system. There is a cointegration relationship between lntpf and lngdp, and there is a long-term and stable equilibrium relationship between sequence lntpf and lngdp. The elasticity of added value of logistics industry to carbon emissions is 1.3729 , which means that the logistics industry will increase by $1 \%$, and the carbon emissions will increase by $1.3729 \%$. 
Table 5.Unit root test for residual sequence

\begin{tabular}{ccccc}
\hline variable & $5 \%$ critical value & ADF & P-value & stablity \\
\hline$\hat{\mathrm{u}}_{\mathrm{t}}$ & -3.4689 & -3.1149 & 0.1294 & unstable \\
\hline$\hat{\mathrm{e}}_{\mathrm{t}}$ & -3.0998 & -3.9197 & 0.0116 & stable \\
\hline
\end{tabular}

$$
\begin{aligned}
& \text { Lntpf }=-2.9048+1.37291 \text { lngdp }+ \text { ût } \\
& \text { t } \quad(-1.01762) \quad(4.72653) \\
& \hat{\mathrm{E}}_{\mathrm{t}}=0.92207+\hat{\mathrm{u}}_{\mathrm{t}} \\
& \mathrm{t} \quad(9.3702)
\end{aligned}
$$

$$
\text { R-squared }=0.972503 \quad \text { adjusted R-squared }=0.967920 \quad \text { D.W }=2.1353
$$

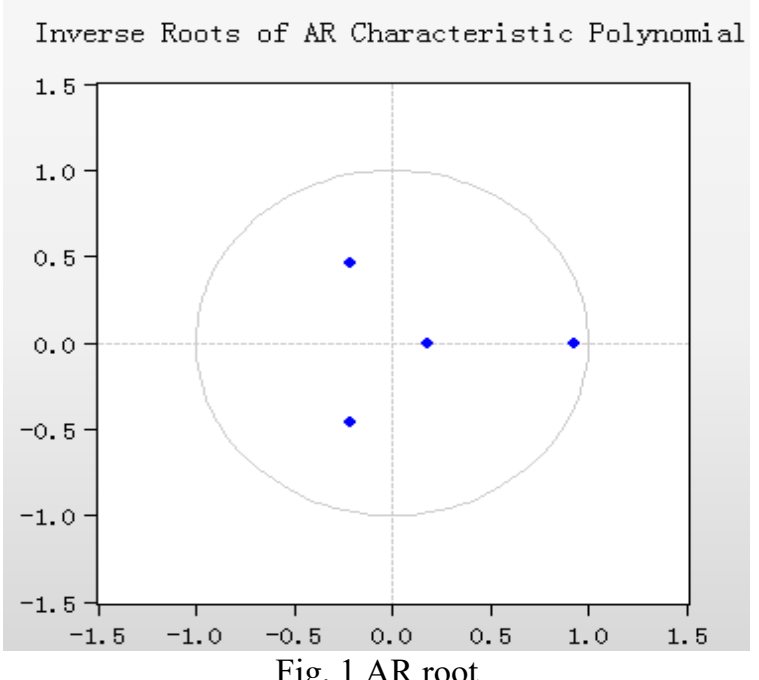

\subsection{Grainger causality test}

Because lntpf and lngdp passed the cointegration test, and then Granger causality test, we selected the data lagging 4 periods to test at the level of $1 \%$ confidence, the results are shown in Table 6 . The results show that carbon emissions are not the Granger cause of the development of logistics industry, and the growth of logistics industry is the Granger cause of carbon emissions.

Table 5.Granger causality test

\begin{tabular}{ccccc}
\hline Null Hypothesis: & obs & F-value & P-value & conclusion \\
\hline Dlntpf does not Granger Cause Dlngdp & 12 & 27.1583 & 0.007 & accept \\
\hline Dlngdp does not Granger Cause Dlntpf & & 0.41731 & 0.791 & refuse \\
\hline
\end{tabular}

\section{Conclusion and suggestion}

Through the unit root test, co-integration test and Granger causality test, the following conclusions are drawn: the original sequence of logistics and carbon emissions in Guangdong Province is unstable, and there is a long-term equilibrium relationship between logistics development and carbon emissions in logistics industry;There is a one-way Granger causality between the development of logistics industry and carbon emission of logistics industry. Carbon emission of logistics industry is not the Granger cause of the development of logistics industry, the development of logistics industry is the Granger cause of carbon emission of logistics industry. For the low carbon development of Guangdong's logistics industry, the following suggestions are put forward:

\subsection{Establishing a long-term low carbon policy mechanism}

The Guangdong Provincial Government should speed up the formulation of low-carbon logistics laws and regulations, guide the logistics industry to take the road of low-carbon through the compulsory force of laws and regulations, set low-carbon measurable standards for logistics 
enterprises through vehicle technical standards, packaging size standards, loading tools standards and other means, and formulating the total carbon emission of enterprises and implementing supervision and rewards and punishments for enterprises.Increase the budget for research and development of low-carbon technologies, increase financial support, tax incentives or loan discounts for low-carbon enterprises such as those using new energy to encourage low-carbon development.Carbon tax should be levied, a carbon fee system should be established, and a carbon tax should be levied on high-polluting and high-emission enterprises, forcing them to update equipment, reduce carbon emissions and environmental pollution.

\subsection{Strengthening logistics low carbon awareness and training logistics low carbon talents}

Strengthen the publicity of low-carbon logistics, through the public transport set up television advertising and other ways to promote low-carbon logistics; some leading enterprises in the logistics industry to play a leading role, adopt low-carbon packaging, e-sheets and other ways to reduce energy consumption. Logistics enterprises can also hold more meetings to publicize low carbon thinking and grasp new low carbon theories and technologies.Low-carbon logistics is not a slogan, we can see its long-term value through the implementation of people, and low-carbon logistics is a long-term process, Guangdong Province government and universities should recognize the importance of low-carbon logistics personnel training, through School-enterprise Cooperation to establish a long-term mechanism for low-carbon logistics personnel training,export more talents for enterprises.

\subsection{Increase logistics and energy saving technology research and development}

Among the total carbon emissions in Guangdong Province, the total amount of carbon emissions from oil products is the largest, so the logistics industry should try to introduce new energy vehicles and promote electric forklift trucks, reduce fuel consumption and carbon emissions, and constantly develop energy-saving and emission-reduction technologies to improve energy efficiency; increase the number of charging stations and charging stations to facilitate the use of natural gas vehicles, electric vehicles and electric forklift trucks, improve the infrastructure of new energy use, such as through mobile APP to find charging points and reserve charging; Logistics enterprises should rationally optimize the distribution route, reduce the no-load and roundabout rate, at the same time, reduce the traffic congestion caused by the logistics industry by traffic control, improve the efficiency of logistics transportation.

\section{Acknowledgement}

This research was financially supported by Heyuan science and technology project( 2018-51) and Heyuan philosophy and Social Sciences 13th Five-Year plan project (HYSK16P01).

\section{References}

[1] Liang Wen, Study on the dynamic relationship between logistics industry and carbon emission based on VAR Model--Taking Anhui Province as an Example, Resource Development and Marketvol,vol.32, pp. 107-111, 2016.

[2] Ouyang Qiangbin, Empirical analysis of carbon emissions in logistics industry, Chongqing and world, vol.7, pp. 4-6, 2011.

[3] Licheng Sun, Low-carbon city logistics distributionnetwork design with resource deployment, Journal of Cleaner Production, vol. 10, pp. 223-228, 2016. 